\title{
Evaluations of poetry readings of English and drama professors
}

\author{
LYNN CHAKOIAN and DANIEL C. O'CONNELL \\ Loyola University of Chicago, Chicago, Illinois 60626
}

\begin{abstract}
Poetry readings by a group of English professors and a group of drama professors were evaluated by 64 adult subjects. Readings of both e. e. cummings' "Dying is Fine" and W. C. Williams' "Botticellian Trees" by the drama professors were judged to be significantly more expressive than readings by English professors. The findings confirm the conclusions of a previous study based on the incidence of more frequent, longer, silent pauses $(>1.2 \mathrm{sec})$ and fewer shorter ones in readings by drama professors compared with those by English professors.
\end{abstract}

Reading poetry aloud is a very specialized, infrequent behavior, the empirical analysis of which has been even rarer. Funkhouser and O'Connell (1978, p. 390) have acknowledged a number of historical suggestions of such analyses that have largely gone unheeded "in favor of more intuitive methods."

There have always been scattered efforts at such empirical analysis within or, better, peripheral to the traditions of modern psychology (Dillon, 1976; Fónagy, 1960; Meinhold, 1967; Snell, 1918a, 1918b; Wallin, 1901; Weithase, 1968), which have remained isolated studies. More recently, a series of articles has pursued the specifically expressive and rhetorical functions of temporal aspects of poetry readings (Funkhouser, 1979a, 1979b; Funkhouser \& O'Connell, 1978, in press; Kowal, O'Connell, O'Brien, \& Bryant, 1975; O'Connell, 1980).

The last mentioned of these provides the starting point for the present research. Two groups of subjects, eight English professors and eight drama professors, individually read e. e. cummings" "Dying is Fine" (DF) and W. C. Williams' "Botticellian Trees" (BT). The drama professors used more longer silent pauses $(>1.2 \mathrm{sec})$ and fewer shorter ones than the English professors. These results were interpreted in terms of rhetorical expressiveness.

The interpretation of expressiveness could well be considered tentative at this juncture. There is, indeed, evidence available that a dominant pattern of relatively longer silent pauses is considered more expressive by listeners. Such were the findings of Clemmer, O'Connell, and Loui (1979), but their data were prose readings by drama students and college graduates. In general, it has also been found that poets read their own poems more slowly than do professors or other adult groups (Funkhouser \& O’Connell, 1978; O’Connell, 1980); their speech and articulation rates are generally very slow, and their silent pauses are longer. One surely could argue that the whole purpose of an artist's reading of his own work is an expressive communication. Still, the next step remains to present to listeners the evidence on which the expressive hypothesis has been based and to find whether their evaluations confirm it.

This is exactly what has been done in the present study in the expectation that the drama professors would be judged significantly more expressive in their readings than the English professors. The ratings of expressiveness elicited from listeners should in turn be expected to be positively correlated with the proportion of pauses $>1.2 \mathrm{sec}$ characteristic of a given reading.

\section{METHOD}

Experimental materials consisted of the readings of DF and BT from O'Connell (1980). These were rerecorded so that each derivative recording had a randomized sequence and selection of the following four types: (1) a reading of DF by an English professor, (2) a reading of DF by a drama professor, (3) a reading of BT by an English professor, and (4) a reading of BT by a drama professor.

There were 64 subjects ( 33 women and 31 men). Of these, 51 were undergraduate students, 6 were graduate students, and the remainder were older adults. Subjects were run in eight groups of eight. Each group was instructed that the experimenter was interested in "your subjective view and opinion of poetry readings." Subjects were told what poems were being used and who the authors were. They were given typed copies of DF and BT "to look over for a few minutes." The sequence for each reading was then (1) preliminary playing, (2) distribution of the questionnaire and explanation of the 1 (very poor) to 5 (very good) scale, (3) a second playing, (4) a third playing, and (5) collection of the questionnaire as each subject finished it. The specific questions regarding expressiveness were (1) how would you rate the appropriateness in amount of emotion expressed through the reading, and (2) how well do you feel the reader expressed emotions appropriate to the passage? For each professor's reading of each poem, a score was obtained by averaging the ratings for these two questions across all eight subjects in the group. This then constituted the expressiveness rating for a given reading of a given poem.

\section{RESULTS}

There was no experimental hypothesis regarding the differential expressiveness ratings of the two poems. In fact, if the questions really tested the subject's evaluation of the reader, one should expect no systematic 
difference in expressiveness ratings between DF and BT. The mean ratings over all readings were 2.97 for DF and 2.77 for BT, quite in keeping with such an expectation.

Between the two experimental groups represented in the readings, however, there was a significant difference. The mean expressiveness rating for readings by the English professors was $2.38(\mathrm{SD}=.69)$, compared with $3.36(\mathrm{SD}=.72)$ for the drama professors $[\mathrm{t}(30)=$ $5.44, \mathrm{p}<.005]$.

Since it had been hypothesized that the difference between expressiveness ratings for English and drama professors would also prove to be related to the greater incidence of longer silent pauses (and the corresponding lesser incidence of shorter pauses) in readings by the drama professors, rank-order correlations were calculated between expressiveness ratings and the proportion of silent pauses $>1.2 \mathrm{sec}$ in length. For all readings taken together, $R=+.33[t(30)=1.92, p<.05]$. For the individual poems, only the correlation for BT was significant $[\mathrm{R}=+.53 ; \mathrm{t}(14)=2.34, \mathrm{p}<.025]$. For $\mathrm{DF}$, the correlation was nonsignificant $(\mathrm{R}=+.23)$.

\section{DISCUSSION}

The isolated statement that a group of English professors read a couple of poems differently from a group of drama professors could well be considered quite trivial. The expressiveness ratings found in the present research, however, clearly indicate that the two sets of readings are perceived by listeners as differentially expressive. The finding is in complete accord with the findings of Clemmer et al. $(1979$, p. 402) for a dramatic prose reading: "Advanced drama students clearly use fewer silent pauses of short and average lengths (up to $800 \mathrm{msec}$ ) and more of longer lengths than the other groups. In fact, they use almost as many silent pauses longer than $1200 \mathrm{msec}$ as do both other groups combined $(63<64)$ and use silent pauses longer than $2000 \mathrm{msec}$ nine times as compared with only one case in both the other groups combined." Expressiveness ratings of the readings of these advanced drama students were made by two drama professors and a group of nonprofessional judges and were significantly more favorable than ratings of readings by beginning drama students or college graduates.

In the present research, the superior ratings of expressiveness for the drama professors corresponded to a similar temporal pattern (O'Connell, 1980). The drama professors had fewer shorter silent pauses $(177<243)$ than the English professors and more longer ones $(45>23)$. Correspondingly, the mean length of their silent pauses was longer $(838>663 \mathrm{msec})$ than the English professors'.

What is clear in all this is that the difference between the expressiveness ratings for the English and drama professors' readings can be accounted for partly by temporal factors, as reflected in the mean length of silent pauses, proportion of longer and shorter pauses, and number of pauses.

It would be a mistake to put too much weight on any or all of these measures. There are other performance variables, as suggested by O'Connell (1980), including rhythm, pitch, stress, and intonational contour, that differentiate such readings and may likely affect expressiveness ratings.

Furthermore, room must be made for a much more nuanced concept of expressiveness. In principle, it must be possible to read or speak expressively without long silent pauses and at a very rapid pace to express, for example, haste, excitement, or vigor. The point to be made is emphatically not that expressiveness has only a slow mode, but simply that expressiveness is a determinant of performance and has predictable, lawful modes of performance.

Again, this might all be considered intuitively clear and inevitable, except that it is diametrically opposed to two theoretical components of modern mainstream psycholinguistics: the classical concept of the ideal speaker and the uniquely cognitive theory of the function of temporal phenomena in speech production.

The first of these, the theory of the ideal delivery, is enunciated in its most forthright form by Clark and Clark (1977, p. 261): "For there to be a speech 'error' there must be a 'correct' way of executing a sentence, and this will be called the ideal delivery. When people know what they want to say and say it fluently, they are giving an ideal delivery. Actors saying their lines, except when making deliberate errors, come close to the ideal delivery, and so do practiced readers and orators. For theories of speech production the ideal delivery is of central importance. They all assume that people strive for the ideal delivery, and every deviation points to something that has gone wrong in planning or execution." The fallacy lies in localizing ideal delivery in the sentence itself. The fact is that there is no single "correct" way of executing any sentence. Ideal delivery is to be localized not solely in what is spoken, but primarily in the speaker's communicative intent. And here is precisely the relevance of expressiveness, for expressiveness is a function of both the emotional, affective state of the speaker (as well as the cognitive) and the relationship of the speaker to an audience. It is not dictated by some Platonic entity called the sentence (see O'Connell, 1977), but by "an intersubjectively established, temporarily shared social world" (Rommetveit, 1974, p. 29). A concept of the ideal delivery is indeed central to any comprehensive theory of speech production, but not the concept of ideal delivery presented by Clark and Clark.

The second component of modern mainstream psycholinguistics engaged by expressiveness research is the uniquely cognitive theory of the function of temporal phenomena in speech production. As Zajonc (1980, p. 152) has bluntly alleged, "contemporary cognitive psychology simply ignores affect." Accordingly, Clark and Clark $(1977$, p. 261) contend that what makes speakers stop when they do is "the selection of words." This planning function is indeed uniquely cognitive and is characteristic of psycholinguistic explanations of temporal phenomena in speech production. Expressiveness, however, clearly requires both an affective component and a listenerrelated component. In other words, rhetoric is intended for a listener, an audience, and is intended to express the affective as well as the cognitive content of the speaker's integral message.

Poetry provides a unique monologic behavioral testing ground for the functions of temporal phenomena in speech. No other speech genre has both the simplicity and the nuances to elicit from readers such a rich variety of rhetorical usage.

\section{REFERENCES}

Clark, H. H., \& Clark, E. V. Psychology and language: An introduction to psycholinguistics. New York: Harcourt Brace Jovanovich, 1977.

Clemmer, E. J., O'Connell, D. C., \& Loui, W. Rhetorical pauses in oral reading. Language and Speech, 1979, 22, 397-405.

Dillon, G. L. Clause, pause, and punctuation in poetry. Linguistics, 1976, 169, 5-20.

Fónagy, I. Die Redepausen in der Dichtung. Phonetica, 1960, 5, 169-203.

Funkhouser, L. Acoustical rhythms in "Buffalo Bill's." Journal of Modern Literature, 1979, 7, 219-242. (a)

Funkhouser, L. Acoustic rhythm in Randall Jarrell's "The Death of the Ball Turret Gunner." Poetics, 1979, 8, 381-403. (b) Funkhouser, L., \& O'Connell, D. C. Temporal aspects of 
poetry readings by authors and adults. Bulletin of the Psychonomic Society, 1978, 12, 390-392.

Funkhouser, L., \& O'Connel., D. C. Cummings reads cummings. Linguistics in Literature, in press.

Kowal, S., O'Connell, D. C., O'Brien, E. A., \& Bryant, E. T. Temporal aspects of reading and speaking: Three experiments. American Journal of Psychology, 1975, 88, 549-569.

Meinhold, G. Quantităt und Häufigkeit von Pausen in Gelesenen deutschen Texten in Zusammenang mit dem Sprechtempo. Wissenschaftliche Zeitschrift der Friedrich-Schiller-Universität Jena, 1967, 1, 107-111.

O'Connell, D. C. One of many units: The sentence. In S. Rosenberg (Ed.), Sentence production: Developments in research and theory. Hillsdale, N.J: Erlbaum, 1977.

O'Connell, D. C. Toward an empirical rhetoric: Some comparisons of expressiveness in poetry readings by authors, English professors, and drama professors. Archiv für Psychologie, 1980, 133, 117-128.

Rommetveit, R. On message structure: $A$ framework for the study of language and communication. New York: Wiley, 1974.
SNell, A. L. F. An objective study of syllabic quantity in English verse. Publication of the Modern Language Association, 1918, 33, 396-408. (a)

Snell, A. L. F. Pause: A study of its nature and its rhythmical function in verse, especially blank verse. In F. N. Scott (Ed.), Contributions to rhetorical theory (Vol. 8). Ann Arbor, Mich: Ann Arbor Press, 1918. (b)

Wallin, J. E. Research on the rhythm of speech. Studies from the Yale Psychological Laboratory (Vol. 9). New Haven: Yale University Press, 1901.

Weithase, I. Experimentelle Auswertung von Tonträgern zur Untersuchung des Sprechstils. In H. Geissner \& W. L. Höffe (Eds.), Sprechen-Horen-Verstehen (Vol. 1). Sprache und Sprechen. Wuppertal, West Germany: A. Henn Verlag, 1968.

Zajonc, R. B. Feeling and thinking: Preferences need no inferences. American Psychologist, 1980, 35, 151-175.

(Received for publication August 20, 1981.) 